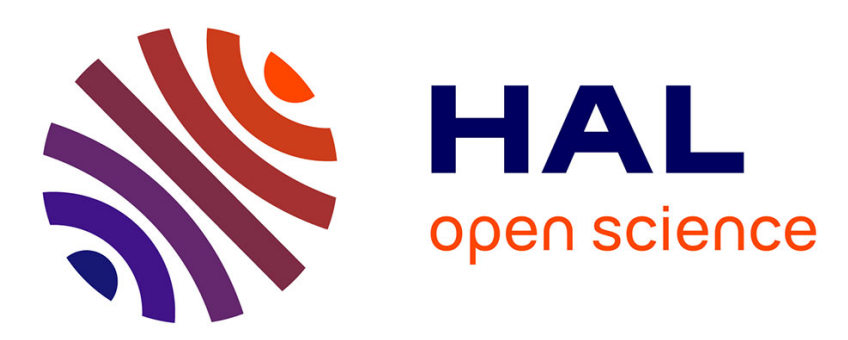

\title{
A near-infrared emitting MOF: controlled encapsulation of a fluorescein sensitizer at the time of crystal growth
} Guillaume Collet, Antonio Hrvat, Svetlana Eliseeva, Céline Besnard, Anton Kovalenko, Stephane Petoud

\section{- To cite this version:}

Guillaume Collet, Antonio Hrvat, Svetlana Eliseeva, Céline Besnard, Anton Kovalenko, et al.. A near-infrared emitting MOF: controlled encapsulation of a fluorescein sensitizer at the time of crystal growth. Chemical Communications, 2021, 57 (27), pp.3351-3354. 10.1039/d0cc08234a . hal03192826

\section{HAL Id: hal-03192826 \\ https://hal.science/hal-03192826}

Submitted on 8 Apr 2021

HAL is a multi-disciplinary open access archive for the deposit and dissemination of scientific research documents, whether they are published or not. The documents may come from teaching and research institutions in France or abroad, or from public or private research centers.
L'archive ouverte pluridisciplinaire HAL, est destinée au dépôt et à la diffusion de documents scientifiques de niveau recherche, publiés ou non, émanant des établissements d'enseignement et de recherche français ou étrangers, des laboratoires publics ou privés. 
Received 00th January 20xx, Accepted 00th January 20xx DOI: $10.1039 / x 0 x \times 00000 x$

\title{
A Near-infrared Emitting MOF Excited with a Low Energy Wavelength: Controlled Encapsulation of Fluorescein Sensitizer at the Time of Crystals Growtht
}

\author{
Guillaume Collet, ${ }^{\mathrm{a}, \mathrm{b}}$ Antonio Hrvat, ${ }^{\mathrm{a}, \mathrm{c}}$ Svetlana V. Eliseeva, ${ }^{\mathrm{a}}$ Céline Besnard, ${ }^{\mathrm{d}}$ Anton Kovalenko ${ }^{\mathrm{a}}$
} Guillaume Collet, $^{\mathrm{a}, \mathrm{b}}$ Anto
and Stéphane Petoud ${ }^{* a}$

We report here a near-infrared (NIR) emitting lanthanide-based metal-organic framework (MOF) in which $\mathrm{Yb}^{3+}$ cations are sensitized by fluorescein (FL) as a low energy absorbing chromophore (FL@CD-MOF-161). The unique design of CD-MOF161 allows for the entrapment of FL molecules in its pores during the synthesis and crystal growth, ensuring the efficient loading and spreading of chromophores within the crystal volume.

The emission in the near-infrared (NIR) spectral range offers breakthrough perspectives in fields of applications such as material science and biology. As examples, NIR-emitting probes and materials have a strong potential for the creation of secret tags and night-vision devices ${ }^{1}$ while the in vivo fluorescent optical imaging will benefit from an improved light penetration due to a reduced tissue absorption, a lower scattering and the minimization of the detrimental contribution of tissues autofluorescence. ${ }^{1-3}$ NIR signals can be advantageously used for diagnostic imaging in which the ability to accurately detect small foci is a key advantage to act early in order to treat a pathology. ${ }^{4}$ The applications for intra-operative optical imaging and guided surgery can also be considered with NIR wavelengths as they allow to perform surgical acts in ambient light. 5, 6

Despite the large amount of attractive theoretical evidences related to the use of NIR signals for in vivo imaging and promising experimental demonstrations $\mathrm{s}^{3,7}$, the number of NIR-emitting probes that can potentially be used in vivo remains scarce. The chemistry and the spectroscopy of lanthanide(III) cations $\left(\mathrm{Ln}^{3+}\right)$ is an active field of research as several of them have a unique potential to fulfil the needs described above by emitting light at wavelengths above 800

\footnotetext{
a. Centre de Biophysique Moléculaire (CBM), CNRS UPR4301. Rue Charles Sadron, 45071 Orléans Cedex 2, France

b. Le Studium Loire Valley Institute for Advanced Studies, Orléans \& Tours, France

c. Current address: Department of Otorhinolaryngology. University Hospital Essen. University of Duisburg-Essen, Essen, Germany

d. Laboratory of Crystallography. University of Geneva, 30 Quai E. Ansermet, $\mathrm{CH}$ 1211 Geneva 4, Switzerland

+ Electronic Supplementary Information (ESI) available: Experimental details and supplementary figures. See DOI: 10.1039/x0xx00000x
}

nm. ${ }^{8,9} \mathrm{In}$ addition, $\mathrm{Ln}^{3+}$ offer complementary advantages such as very narrow emission bands, the wavelengths of which are not affected by experimental conditions $(\mathrm{pH}$, temperature, biological environment). ${ }^{10}$ Moreover, most of $\mathrm{Ln}^{3+}$-based compounds are insensitive to photobleaching which allows (i) their excitation with powerful sources such as lasers, (ii) the extension of the experimental time or their repetition.

As most of $f-f$ transitions are forbidden resulting in very low absorption coefficients of free $\mathrm{Ln}^{3+}$, the presence of highly absorbing sensitizers is required to generate their characteristic emission, an approach named "antenna effect" ${ }^{9}$ In this process, the antenna absorbs the light from the excitation source and transfers the resulting energy to the accepting electronic levels of the $\mathrm{Ln}^{3+}$ resulting in the enhancement of its emission intensity. ${ }^{9,}{ }^{11}$ The antenna effect is mainly controlled by the electronic structure of the sensitizing chromophore, by the nature of the $\mathrm{Ln}^{3+}$, by the $\mathrm{Ln}^{3+}$ sensitizer distance and by their ratio. Various approaches have been tested to obtain such sensitization. ${ }^{12}$ The vast majority of $\mathrm{Ln}^{3+}$ compounds described in the literature have excitation wavelengths located in the UV range. Such high energy light can induce damages to biological systems. Another limitation of most of currently described $\mathrm{Ln}^{3+}$ compounds emitting in the NIR are their quantum yield values that are often modest. To create $\mathrm{Ln}^{3+}$ compounds able to emit a large number of photons despite low quantum yields, we took advantage here of the "polymetallic" approach that we have used previously in which a high density of luminescent $\mathrm{Ln}^{3+}$ and sensitizers are located in a given volume. ${ }^{10,13,14}$ To achieve this goal, the use of metal-organic frameworks (MOFs) is of particular interest due to the unique rigidity and the crystalline nature of this family of materials. ${ }^{15}$ The specific advantages are (i) the precise location of all atoms determined by single crystal crystallography, including $\mathrm{Ln}^{3+}$ and distances separating them allowing the rationalization of their photophysical properties, (ii) the possibility to synthesize large amounts of materials that are often essential for practical applications and (iii) the use of MOFs as carriers of molecules, drugs, etc. within their pores. ${ }^{16-18}$

Several structures of MOFs have been used for the sensitization 


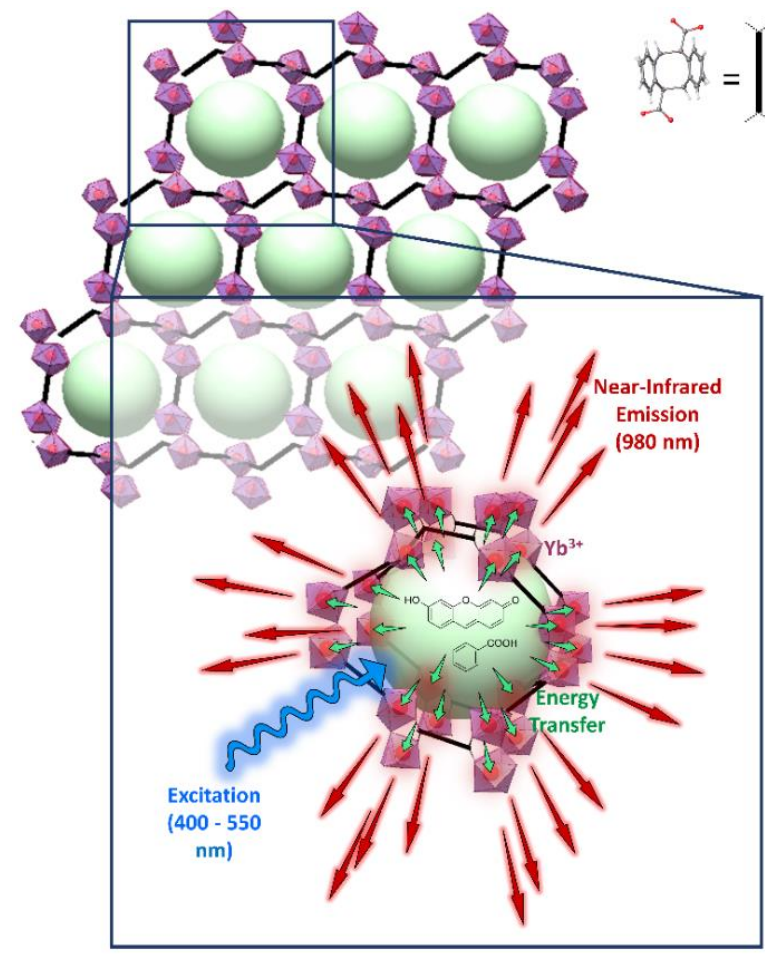

Figure 1. Schematic representation of the NIR-emitting FL@CD-MOF-161. Ligands black lines; $\mathrm{Yb}^{3+}$ and its coordination sphere: red and purple; $\mathrm{FL}$ : green spheres The cartoon in the square exemplifies the $\mathrm{Yb}^{3+}$ sensitization mechanism: the followed by the energy transfer to $\mathrm{Yb}^{3+}$ which emits a narrow NIR signal with maximum at $980 \mathrm{~nm}$.

of NIR-emitting $\mathrm{Ln}^{3+}$, however only a few of them demonstrated to be compatible with practical applications such as biological imaging. ${ }^{19-22}$ As a major breakthrough, we have described in 2013 the first example of the use of a nano-MOF as a NIR-imaging agent in living cells. ${ }^{13}$ The limitation of this MOF is the excitation wavelength around $355 \mathrm{~nm}$ which is incompatible for in vivo biological imaging. Moreover, the excitation wavelength of this system is controlled by the nature of the rigid chromophoric ligand that is forming the network. To shift the excitation wavelength toward lower energy, we have tested different post-synthetic strategies, including the entrapment of chromophores such as the LDS 750 into pores of the widely used $\mathrm{Yb}^{3+}$-BPDC MOF, 20 the covalent modification of MOF linkers, ${ }^{23}$ or the in-situ coupling of acetylene units to form a high density of $\pi$-conjugated systems throughout MOF pores. ${ }^{24}$ An alternative strategy for long-wavelength excitation of NIR-emitting compounds would be by two-photon absorption. However, such approach requires the use of specific equipment including femtosecond lasers. ${ }^{25,} 26$

One of the originalities of the present work lies in the design, synthesis and characterization of a new NIR-emitting $\mathrm{Yb}^{3+}$-based MOF (FL@CD-MOF-161, Figure 1, S1-2) that possesses a biocompatible excitation wavelength. Fluorescein (FL) has been described as sensitizing the NIR emission of $\mathrm{Yb}^{3+}$ and exhibits a high absorption of light in the range of 400-550 nm $\left(\varepsilon>10^{5} \mathrm{M}^{-1} \mathrm{~cm}^{-1}\right) .{ }^{27}$ When exposed to excitation light, a NIR emission signal arises from $\mathrm{Yb}^{3+}$ cations that are used as coordination metals ions in FL@CDMOF-161. In this tridimensional system, FL molecules located inside the MOF pores act as antennae to sensitize $\mathrm{Yb}^{3+}$
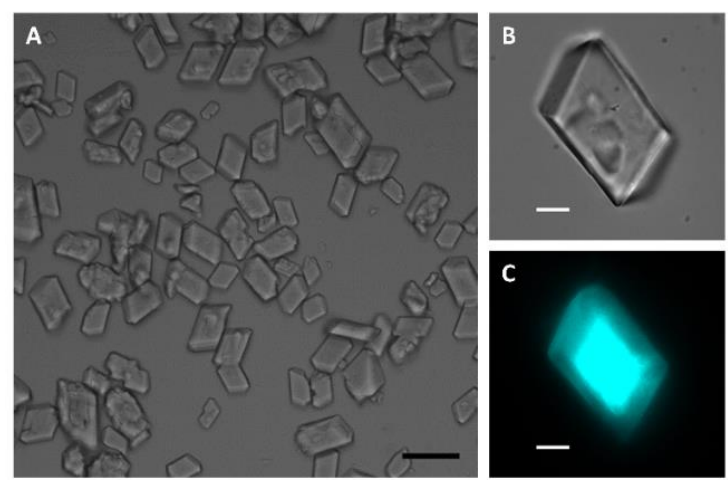

Figure 2. Optical microscopy images of FL@CD-MOF-161 crystals. (A) Brightfield objective $20 x$, scale bar: $50 \mu \mathrm{m}$. (B) Brightfield, objective $60 \times$, scale bar: $10 \mu \mathrm{m}$. (C) NIR luminescence. $\lambda_{\text {ex }}: 482 \mathrm{~nm}$ band pass $35 \mathrm{~nm}, \lambda_{\mathrm{em}}: 996 \mathrm{~nm}$ band pass $70 \mathrm{~nm}$ $\tau_{\text {exp }}: 100 \mathrm{~ms}$, objective $60 \times$, scale bar: $10 \mu \mathrm{m}$.

As an additional novelty and advantage of our work, the FL has been introduced during MOF assembly at the time of crystal growth, leading to an easy, controlled and efficient loading up to the centres of crystals in contrast to a post-synthesis loading which is limited by diffusion. ${ }^{16}$

The new FL@CD-MOF-161 was synthesized using a methodology inspired by a protocol that we had described recently combining 9anthracene carboxylic acid dimers (Di-9AC) as ligands, $\mathrm{Yb}^{3+}$ as coordination metal ions and $\mathrm{FL} .{ }^{28}$ Crystallites with sizes around $50 \mu \mathrm{m}$ were isolated (Figure 2A, 2B, S3), showing a high level of reproducibility from one synthesis to another. They emit in the NIR range upon excitation at $400-550 \mathrm{~nm}$ (Figure 2C, S3). The PXRD analysis confirmed the isostructural nature of FL@CD-MOF-161 with the previously described CD-MOF-161 (Figure S4). ${ }^{28}$ Therefore, the presence of the FL does not affect the structure of the CD-MOF-161. Monitoring the FL emission by itself, its distribution inside the entire volume of crystals was evaluated by confocal laser scanning microscopy. Resulting pictures show that FL molecules are entrapped in the CD-MOF-161 structure up to the crystal centre and are indeed distributed evenly inside the entire volume (Figure S5-7).

The photophysical properties of the FL@CD-MOF-161 crystals have been evaluated. The diffuse reflectance spectrum exhibits broad bands in the range $400-550 \mathrm{~nm}$ that correspond to typical FL absorption (Figure S8). Emission spectra were collected upon excitation at $480 \mathrm{~nm}$. These data reveal the presence of a NIR emission band with a barycentre at $980 \mathrm{~nm}$ which can be attributed to the $\mathrm{Yb}^{3+2} \mathrm{~F}_{5 / 2} \rightarrow{ }^{2} \mathrm{~F}_{7 / 2}$ transition (Figure 3). As $\mathrm{Yb}^{3+}$ does not possess electronic levels in the energy domain corresponding to the visible range $^{29}$ and as the Di-9AC ligands that form the architecture of the CD-MOF-161 exhibit absorption bands below $300 \mathrm{~nm}$, the only way to sensitize $\mathrm{Yb}^{3+}$ upon excitation at $480 \mathrm{~nm}$ is through the "antenna effect", i.e. energy transfer from the excited electronic states of the FL encapsulated in the pores of the MOFs to the accepting levels of $\mathrm{Yb}^{3+} .{ }^{9}$ Moreover, the excitation spectrum (Figure 3, left) recorded upon monitoring $\mathrm{Yb}^{3+}$ emission at $980 \mathrm{~nm}$ coincides well with the diffuse reflectance spectrum (Figure S8). This type of sensitization process results in a large difference in energy $(\sim 500 \mathrm{~nm})$ between the maxima of the excitation and the emission wavelengths observed for FL@CD-MOF-161 crystals. Such large energy shift represents an important advantage for optical imaging experiments since the 


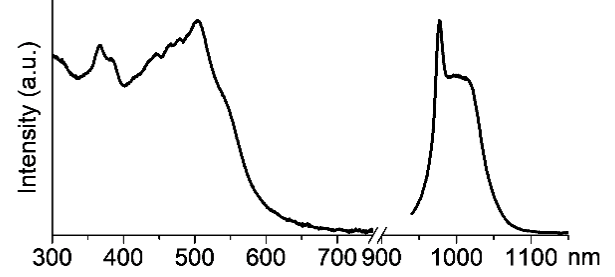

Figure 3. Corrected and normalized (left) excitation $\left(\lambda_{\text {ex }}=480 \mathrm{~nm}\right)$ and (right) emission $\left(\lambda_{\text {em }}=980 \mathrm{~nm}\right)$ spectra of FL@CD-MOF-161 crystals at room temperature.

entire emission signal can be collected without taking into account (i) a compromise in filters choice as it is the case with most organic fluorophores due to small Stokes shift, (ii) the possible reabsorption by organic dyes of their own emitted photons, minimizing consequently the intensity of the detected signal. It is worth noting that the emission spectrum observed for the FL-free CD-MOF-161 crystals upon a $480 \mathrm{~nm}$ excitation does not contain any $\mathrm{Yb}^{3+}$-centred emission bands in the range of 940-1100 nm, confirming that the NIR signal arising from FL@ CD-MOF-161 is indeed obtained by the FLmediated sensitization (Figure S9). However, the sensitization process is not quantitative and the residual broad-band emission of $\mathrm{FL}$ in the visible range was observed upon $480 \mathrm{~nm}$ excitation (Figure S13). $\mathrm{Yb}^{3+}$-centred quantum yields $\left(Q_{Y b}^{L}\right)$ were determined in order to quantify the efficiency of the FL@CD-MOF-161 to convert the excitation light absorbed by the FL to generate the NIR emission of $\mathrm{Yb}^{3+}$. A $Q_{Y b}^{L}$ value of $0.308(3) \%$ was obtained (Table S1). Remarkably, this value is 15- to 30 -times larger than those observed for the postsynthetically modified MOF-1114(Yb) and MOF-1140(Yb), or for the LDS750@ $\mathrm{Yb}^{3+}-$ BPDC that we have described previously, demonstrating a much higher sensitization efficiency. ${ }^{20,} 24$ The experimental luminescence decay recorded for the FL@CD-MOF-161 crystals upon monitoring $\mathrm{Yb}^{3+}$ emission is best fitted by a threeexponential function indicating the presence of emissive $\mathrm{Yb}^{3+}$ in different coordination environments (Table S1). The calculated average lifetime value of the ${ }^{2} \mathrm{~F}_{5 / 2}$ state is equal to $10.8 \mu \mathrm{s}$ and is at least 2-times longer than those recorded for the other low-energy absorbing MOF-1114(Yb) and MOF-1140(Yb), or for the LDS750@ @ b $^{3+-B P D C}$ that we have reported previously. ${ }^{20,} 24$ Such results probably reflect a better protection of $\mathrm{Yb}^{3+}$ in FL@CD-MOF161 from high-energy vibrations.

Chemical stability of materials during extended periods of storage as well as the stability under continuous illumination referred to as photostability are both crucial properties to consider in view of potential applications. Both parameters were evaluated for FL@CD-MOF-161 crystals. The exact match of PXRD patterns recorded on freshly synthesized samples and on samples stored for one year in quartz capillaries at room temperature without protection from light (Figure S10) confirmed the extremely high stability of FL@CD-MOF-161 crystals. This stability was further supported by brightfield microscopy experiments that reveal a high level of similarity of crystals shapes for these two samples. Photophysical studies performed on the sample stored for one year showed that the characteristic $\mathrm{Yb}^{3+}$ emission is still efficiently sensitized by the entrapped FL (Figure S11) while the $Q_{Y b}^{L}$ value
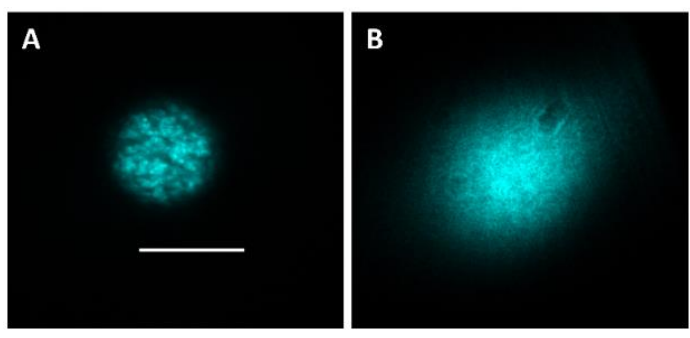

Figure 4. NIR fluorescence images of FL@CD-MOF-161 crystals obtained by epifluorescence macroscopy upon excitation with light selected with a 482 band filter. (A) A capillary filled with crystals (Figure S6) was observed through a mask $\left(500 \mu \mathrm{m}\right.$ of diameter); $\tau_{\text {exp }}: 5 \mathrm{~s}$. (B) The same sample was observed through a $1 \mathrm{~mm}$ thick bio-mimicking phantom tissue positioned on the top of the mask; $\tau_{\text {exp }}: 30 \mathrm{~s}$ Macro-objective 5x; scale bar: $500 \mu \mathrm{m}$.

decreased only by a modest factor of 1.7. On the other hand, the average luminescence lifetime value of the ${ }^{2} \mathrm{~F}_{5 / 2}$ state is 1.4-times longer for the FL@ CD-MOF-161 crystals after the one year storage period (Table S1). Such phenomenon may be due to a redistribution of water, FL and/or DMA molecules inside of the MOF network that impacts the $\mathrm{Yb}^{3+}$ environment(s) and therefore the probabilities of non-radiative deactivations. These changes are also reflected by a slight variation of the relative intensities of the different Stark components of the ${ }^{2} \mathrm{~F}_{5 / 2} \rightarrow{ }^{2} \mathrm{~F}_{7 / 2} \mathrm{Yb}^{3+}$ transition observed in the emission spectrum (Figure S11). It should be noted, however, that the UV-vis absorption spectrum recorded on the supernatant solution of the FL@CD-MOF-161 crystals measured after the one year of storage does not indicate the presence of any traces of free FL (data not shown). Moreover, FL-centered quantum yield in the visible range remains the same after storage (2.2(1)\%). All these results confirm (i) the good stability of FL@CD-MOF-161 crystals over an extended period of time with no requirement of protection of the sample from light and from the temperature, and (ii) the efficient entrapment of FL insides of MOF pores demonstrated by the absence of detectable release. Such absence can be also explained by the perfect docking of the FL molecule in cavities of the MOF, which was confirmed by the crystallography-determined structure Figure S12). In addition, the photostability of FL@CD-MOF-161 crystals upon continuous illumination at $480 \mathrm{~nm}$ was evaluated (Figure S13). Only minor decreases (less than $10 \%$ ) of the $\mathrm{Yb}^{3+}$ signal at $980 \mathrm{~nm}$ or $\mathrm{FL}$ emission in the visible were observed after 2 hours of continuous irradiation, indicating an excellent photostability.

In order to establish a preliminary proof of principle of the FL@CD-MOF-161 to be used as in vivo NIR imaging agent, an epifluorescence macroscopy experiment was performed using a biomimicking phantom tissue. This model system contains haemoglobin and intralipids in order to simulate the absorption and the scattering of excitation and emitted light, respectively, and to reproduce the optical characteristics comparable to living tissues. ${ }^{30} \mathrm{~A}$ mask with a $500 \mu \mathrm{m}$ diameter circular hole was used to spatially simulate a small size emitting foci that potentially could be an early pathological site (Figure 4A). This mask was positioned on the top of a capillary containing crystals of FL@CD-MOF-161 (Figure S14). The 1 mm thick bio-mimicking tissue was placed on the top of the mask and the specific $\mathrm{Yb}^{3+}$ NIR signal was monitored with a 996 band pass $70 \mathrm{~nm}$ filter upon excitation into FL-centred bands (482 band pass $35 \mathrm{~nm}$ filter). One of the important novelty provided by the creation of this 
MOF lies in its ability to efficiently sensitize $\mathrm{Yb}^{3+}$ using an excitation wavelength which is significantly shifted to the visible spectral domain in comparison to the actual NIR-emitting $\mathrm{Ln}^{3+}$ compounds described in the literature. ${ }^{31}, 32$ The reduced autofluorescence present in the NIR allowed to unambiguously record the specific $\mathrm{Yb}^{3+}$ signal through the bio-mimicking phantom tissue (Figure 4B, S15). In addition, this macroscopy experiment was realized in challenging conditions by detecting the signal through a small size focus of 500 $\mu \mathrm{m}$ of diameter, reducing significantly the total amount of collected light. Its success shows that it is possible to monitor the $\mathrm{Yb}^{3+}$ signal, non-invasively, with a good level of sensitivity highlighting the potential of FL@CD-MOF-161 for in vivo imaging.

In conclusion, taking advantage of the rigid cavity of a MOF to encapsulate an organic fluorophore in a controlled way and at the time of crystals growth, we have synthesized an $\mathrm{Yb}^{3+}$-based NIRemitting MOF that can be excited with a low energy wavelength. Quantum yield are higher than those reported by us for other MOF systems with low excitation wavelength. This new MOF system is highly robust, being insensitive to long term storage and to photobleaching. The FL sensitizer remains in the cavity of the MOF. Proof of principle NIR imaging experiments were performed with the excitation and emission light passing through $1 \mathrm{~mm}$ of bio-mimicking phantom tissue. High quality pictures were obtained from the NIR signal arising from $\mathrm{Yb}^{3+}$. These results highlight the promising potential of FL@CD-MOF-161 for NIR imaging and diagnostic applications and ultimately for in vivo imaging.

The result incorporated into this study have received funding from the Ligue Régionale Contre le Cancer, comité du Loiret et d'Eure-et-Loir, the network "Molécules marines, métabolisme et cancer» from the Cancéropôle Grand Ouest, la Région Centre, I'Agence Nationale de la Recherche (NIRA-ANR-13-BS08-0011), the European Union's Horizon 2020 research and innovation programme under the Marie Skłodowska-Curie grant agreement No 665790. A.H. and S.P. acknowledge support from Erasmus+ Programm (HR ZAGREB01) and the Institut National de la Santé et de la Recherche Médicale (INSERM), respectively.

\section{Conflicts of interest}

There are no conflicts to declare.

\section{Notes and references}

1. L. Wang, Z. Zhao, C. Wei, H. Wei, Z. Liu, Z. Bian and C. Huang, Adv. Opt. Mater., 2019, 7, 1801256.

2. J. V. Frangioni, J. Clin. Oncol., 2008, 26, 4012-4021.

3. R. Weissleder and V. Ntziachristos, Nat. Med., 2003, 9, 123 128.

4. R. Etzioni, N. Urban, S. Ramsey, M. McIntosh, S. Schwartz, B. Reid, J. Radich, G. Anderson and L. Hartwell, Nat. Rev. Cancer., 2003, 3, 243-252.

5. K. E. Tipirneni, J. M. Warram, L. S. Moore, A. C. Prince, E. de Boer, A. H. Jani, I. L. Wapnir, J. C. Liao, M. Bouvet, N. K. Behnke, M. T. Hawn, G. A. Poultsides, A. L. Vahrmeijer, W. R. Carroll, K. R. Zinn and E. Rosenthal, Ann. Surg., 2017, 266, 36-47.
6. C. S. Wang, Z. H. Wang, T. Zhao, Y. Li, G. Huang, B. D. Sumer and J. M. Gao, Biomaterials, 2018, 157, 62-75.

7. M. X. Zhang, J. Y. Yue, R. Cui, Z. R. Ma, H. Wan, F. F. Wang, S. J. Zhu, Y. Zhou, Y. Kuang, Y. T. Zhong, D. W. Pang and H. J. Dai, Proc. Natl. Acad Sci. USA, 2018, 115, 6590-6595.

8. Y. Fan, P. Wang, Y. Lu, R. Wang, L. Zhou, X. Zheng, X. Li, J. A. Piper and F. Zhang, Nat. Nanotechnol., 2018, 13, 941-+.

9. H. Uh and S. Petoud, C. R. Chim., 2010, 13, 668-680.

10. K. A. White, D. A. Chengelis, K. A. Gogick, J. Stehman, N. L. Rosi and S. Petoud, J. Am. Chem. Soc., 2009, 131, 1806918071.

11. S. I. Weissman, J. Chem. Phys., 1942, 10, 214-217.

12. Y. Hasegawa, Y. Kitagawa and T. Nakanishi, NPG Asia Mater., 2018, 10, 52-70.

13. A. Foucault-Collet, K. A. Gogick, K. A. White, S. Villette, A. Pallier, G. Collet, C. Kieda, T. Li, S. J. Geib, N. L. Rosi and S. Petoud, Proc. Natl. Acad. Sci. USA, 2013, 110, 17199-17204.

14. A. Douvali, A. C. Tsipis, S. V. Eliseeva, S. Petoud, G. S. Papaefstathiou, C. D. Malliakas, I. Papadas, G. S. Armatas, I. Margiolaki, M. G. Kanatzidis, T. Lazarides and M. J. Manos, Angew. Chem. Int. Ed., 2015, 54, 1651-1656.

15. Y. Cui, J. Zhang, H. He and G. Qian, Chem. Soc. Rev., 2018, 47, 5740-5785.

16. P. Horcajada, C. Serre, M. Vallet-Regi, M. Sebban, F. Taulelle and G. Ferey, Angew. Chem. Inter. Ed., 2006, 45, 5974-5978.

17. A. Jihyun, S. J. Geib and N. L. Rosi, J. Am. Chem. Soc., 2009, 131, 8376.

18. R. C. Huxford, J. Della Rocca and W. Lin, Curr. Opin. Chem. Biol., 2010, 14, 262-262-268.

19. T.-Y. Luo, P. Das, D. L. White, C. Liu, A. Star and N. L. Rosi, J. Am. Chem. Soc., 2020, 142, 2897-2904.

20. C. Liu, S. V. Eliseeva, T. Y. Luo, P. F. Muldoon, S. Petoud and N. L. Rosi, Chem. Sci., 2018, 9, 8099-8102.

21. D. Zou, J. Zhang, Y. Cui and G. Qian, Dalton Trans., 2019, 48 6669-6675.

22. T. N. Nguyen, S. V. Eliseeva, A. Gładysiak, S. Petoud and K. C. Stylianou, J. Mater. Chem. A, 2020, 8, 10188-10192.

23. T.-Y. Luo, C. Liu, S. V. Eliseeva, P. F. Muldoon, S. Petoud and N. L. Rosi, J. Am. Chem. Soc., 2017, 139, 9333-9340.

24. P. F. Muldoon, G. Collet, S. V. Eliseeva, T.-Y. Luo, S. Petoud and N. L. Rosi, J. Am. Chem. Soc., 2020, 142, 8776-8781.

25. N. Hamon, A. Roux, M. Beyler, J.-C. Mulatier, C. Andraud, C. Nguyen, M. Maynadier, N. Bettache, A. Duperray, A.

Grichine, S. Brasselet, M. Gary-Bobo, O. Maury and R. Tripier, J. Am. Chem. Soc., 2020, 142, 10184-10197.

26. A. D'Aléo, A. Bourdolle, S. Brustlein, T. Fauquier, A. Grichine, A. Duperray, P. L. Baldeck, C. Andraud, S. Brasselet and O. Maury, Angew. Chem. Int. Ed., 2012, 51, 6622-6625.

27. G. A. Hebbink, L. Grave, L. A. Woldering, D. N. Reinhoudt and F. van Veggel, J. Phys. Chem. A, 2003, 107, 2483-2491.

28. G. Collet, T. Lathion, C. Besnard, C. Piguet and S. Petoud, J. Am. Chem. Soc., 2018, 140, 10820-10828.

29. W. T. Carnall, in Handbook on the Physics and Chemistry of Rare Earths, ed. K. A. Gschneidner Jr., Eyring, L., North Holland Publ. Co., Amsterdam, 1979, pp. 172-208.

30. R. Pleijhuis, A. Timmermans, J. De Jong, E. De Boer, V. Ntziachristos and G. Van Dam, J. Vis. Exp., 2014, 51776.

31. I. Martinić, S. V. Eliseeva and S. Petoud, J. Lumin., 2017, 189, 19-43.

32. Y. Ning, M. Zhu and J.-L. Zhang, Coord. Chem. Rev., 2019, 399, 213028. 